УДК 316.4

НАТСАК Органа Доржуевна - кандидат философских наук, ученый секретарь Тувинского института гуманитарных и прикладных социально-экономических исследований при Правительстве Республики Тыва (667000, Россия, Республика Тыва, г. Кызыл, ул. Кочетова, 4; под695596@ gmail.com)

\title{
ФИНАНСОВО-ЭКОНОМИЧЕСКИЕ СТРАТЕГИИ ТУВИНСКИХ СЕМЕЙ (по материалам социологических исследований)
}

\begin{abstract}
Аннотация. В статье анализируются финансово-экономические стратегии современных тувинских семей по материалам социологических исследований, проведенных в Республике Тыва в 2019 и 2021 гг. В рамках обозначенной проблемы изучены особенности кредитного, сберегательного поведения разных социально-демографических групп с использованием в Т.ч. статистических данных о доходах, долговой нагрузке населения.

Причиной высокого уровня проникновения кредитов в практику современных тувинских семей является не только недостаточный уровень финансовой грамотности и культуры сбережений, но и объективная монетарная бедность. В статье показано, что высокий уровень демографической нагрузки в республике не способствует развитию накопительных и сберегательных стратегий. Исходя из результатов анализа, можно сделать вывод, что фактическая бедность населения будет расти, если не будет принята особая политика, направленная на развитие региональной экономики, а также на повышение финансовой грамотности и культуры сбережений среди населения республики.

Ключевые слова: доходы и расходы домохозяйств, кредиты, сбережения, экономика тувинских семей, финансовая грамотность, вторичная занятость
\end{abstract}

Постановка проблемы. Республика Тыва имеет ряд социально-демографических и региональных особенностей: это высокая рождаемость, средний размер семьи, превышающий таковой по другим субъектам РФ. Республика считается самым бедным российским регионом, что требует особого внимания к причинам и факторам, способствующим высокому уровню бедности. Исследование бедности, помимо монетарных, депривационных, субъективных и иных подходов к ее измерению, не будет полным без социологического анализа финансово-экономических стратегий семей, поскольку социологические методы помогают раскрыть поведенческие паттерны, способствующие бедности или, наоборот, выходу из бедности. В этой связи поведенческий подход дополняет структурную методологию изучения бедности. Работ с такой постановкой проблемы относительно Республики Тыва в социологической литературе не было.

Целью данной статьи является анализ финансово-экономических стратегий современных тувинских семей на основе социологических исследований. Для достижения обозначенной цели автор определил следующие исследовательские задачи: изучить финансовые стратегии семей через анализ кредитного и сберегательного поведения на основе результатов опросов, статистических данных об уровне долговой нагрузки, соотношении объемов вкладов и задолженности по кредитам в республике; определить факторы, влияющие на финансовое поведение семей.

Методологической основой при подготовке статьи послужили работы зарубежных и российских исследователей в области поведенческой экономики [Акерлоф, Шиллер 2010; Durvasula 2014; Filho, Paiva 2017; Poluektova, Efremova, Breugelmans 2015], исследования, посвященные адаптационным стратегиям 
населения России [Козырева, Смирнов 2016]. Автор ориентировался также на работы, исследующие современные модели финансового поведения населения [Ярашева 2017; Аликперова 2020; Медведева и др. 2016; Шубаева, Наумов 2015]. Кроме того, были использованы аналитические материалы Всемирного банка об использовании поведенческих наук в борьбе с бедностью и повышении справедливости ${ }^{1}$.

Эмпирическая база. На современном этапе первыми в этом исследовательском поле начала работу группа социологов под руководством 3.Т. Голенковой из Центра исследования социальной структуры и социального расслоения Института социологии ФНИСЦ РАН в 2019 и 2021 гг. [Голенкова, Голиусова, Сушко 2020; Голиусова, Кефели 2019; Особенности социальной... 2019]. Результаты этих опросов, а также исследования, проведенные автором, составили эмпирическую базу статьи. Приведем некоторые параметры данных научных проектов.

1. 2019 г. Целью данного исследования было получение данных о структуре и количественном выражении доходов и расходов домохозяйств республики. Объем выборочной совокупности составил 1200 домохозяйств. Исследование проходило в 88 населенных пунктах Республики Тыва. Метод сбора информации - личное интервью с совершеннолетним представителем домохозяйства, принимающим решение в распределении общего бюджета. По итогам его реализации были получены сведения о 1243 домохозяйствах и 4889 членах этих домохозяйств (включая несовершеннолетних детей).

2. 2021 г. Целью исследовательского проекта было изучение социально-экономического положения населения Республики Тыва. Генеральную совокупность, служащую основой для построения выборочной совокупности при проведении исследования, составило все население Республики Тыва старше 18 лет. Размер выборочной совокупности составил 1500 ед. Методом сбора информации являлось 20-минутное личное интервью, которое проводилось по формализованному опроснику.

3. Дополнительным источником информации послужил опрос представителей брачных пар, проведенный автором в декабре 2020 - январе 2021 г. в целях комплексного изучения современной тувинской семьи, который касался репродуктивных, финансово-экономических стратегий, оценки материального состояния, особенностей распределения домашней работы и др. Генеральную совокупность составили все брачные пары, проживающие на территории Республики Тыва. Размер выборочной совокупности составил 450 ед. Методом сбора информации являлось личное интервью с одним представителем брачной пары, проводившееся по формализованному опроснику. В статье использованы также результаты глубинных интервью с жителями Республики Тыва, проведенных автором в ноябре 2021 г.

Информационной основой послужили официальные данные Росстата.

Автор выделяет закредитованность как серьезную проблему на фоне низких показателей занятости, высокой рождаемости, незначительной доли бизнеса в общей структуре занятости и рассматривает кредиты как основной триггер социальных рисков. Следует также учитывать уровень доходов: в ходе исследования 2019 г. 82\% опрошенных домохозяйств отнесли себя к низкодоходным. В качестве причин низких доходов $33,6 \%$ домохозяйств указали низкий уровень оплаты труда, 23,2\% - отсутствие работы по месту жительства; 18,8\%

1 Mind, Behavior, and Development Unit. Applying Behavioral Science to End Poverty and Enhance Equity. World Bank Group, Poverty \& Equity. 2015. URL: https://documents1. worldbank.org/curated/en/744191532458732002/pdf/128784-eMBeD-Brochure-DIGITAL.pdf (accesed 01.02.2022). 
- невысокий размер социальных выплат и пособий; 13,3\% - большое число несовершеннолетних в семье. Анализ разницы между доходной и расходной частью бюджета семей показал, что 38,9\% домохозяйств имели в марте 2019 г. отрицательное сальдо семейного бюджета.

Kредиты. В Республике Тыва наблюдается высокий уровень проникновения кредитования и долговой нагрузки населения. В такой ситуации наиболее уязвимыми может оказаться наименее обеспеченная часть населения. Высокая доля обязательных платежей по кредитам негативно влияет на реальные располагаемые доходы населения, несмотря на индексацию пенсий, зарплат, социальных выплат, введение новых видов социальной поддержки семей с детьми.

С развитием финансовых институтов получение кредитов и покупки в кредит стали обычной практикой в финансовом поведении населения. В последние два-три года потребительское кредитование населения растет как «вширь» (за счет увеличения числа заемщиков), так и «вглубь» (за счет повышения долговой нагрузки, увеличения числа кредитов на 1 заемщика, также растет доля заемщиков, имеющих кредиты по нескольким типам кредитов и/или в различных банках) [Овчарова, Красильникова, Пишняк 2020: 22]. Эта общероссийская тенденция характерна и для Республики Тыва.

Республика Тыва имеет самый высокий суммарный показатель - 38,4 (доля проникновения - отношение числа заемщиков на отчетную дату в регионе к числу постоянно проживающего населения на начало календарного года) по данным Центробанка. Внутри суммарного показателя тревожным является уровень проникновения микрофинансовых организаций (МФО) - 12,9. По уровню проникновения потребительских кредитов на первом месте Республика Алтай, вслед за ней идет Республика Тыва 1 .

Социологическое исследование, проведенное в Республике Тыва в 2021 г., показало, что 51,9\% респондентов имеют кредиты, опрос автора 2020-2021 гг. показал, что кредиты имеют $82,7 \%$ брачных пар.

Каковы социально-демографические характеристики респондентов, пользующихся банковскими кредитами? Материалы исследования 2021 г. показали следующее.

Возрастные групnы. Кредиты получают представители всех без исключения возрастных групп, но в большей степени $(45,8 \%)$ это лица в возрасте $35-54$ лет, менее всех кредиты оформляют представители старшего поколения - 55 лет и более. Среди тех, кто не имеет кредитов, количественно лидируют респонденты 18-34 лет (69,5\% представителей этой возрастной группы).

Уровень образования. Среди лиц, получающих кредиты, больше всех представлены те, кто имеет высшее $(47,5 \%)$ и среднее профессиональное $(37,6 \%)$ образование, наименьшую группу составили лица, не имеющие профессионального образования $(14,1 \%)$.

Занятость. По характеру занятости больше всего кредитами пользуются лица, имеющие постоянную работу $-68,7 \%$ респондентов (см. табл. 1). За этой группой следуют официально зарегистрированные предприниматели $-64,4 \%$. Следует обратить внимание на тот факт, что 41,5\% финансово незащищенной группы (временно не работающие или безработные) также имеют кредиты. С учетом требований банков к наличию работы, подтвержденных доходов, а также к уровню доходов можно допустить, что представители последней группы могут пользоваться услугами микрофинансовых организаций (МФО). По мнению исследователей, МФО позволяют получить доступ к кредиту

1 Ускоренный рост потребительских кредитов в структуре банковского кредитования: причины, риски и меры: доклад. Июнь 2019. М.: Банк России. С. 9. 
людям с низкими доходами, которые в силу экономических причин не могут получить услуги традиционной банковской системы.

Таблица 1

Наличие кредитов среди групा по основному занятию

\begin{tabular}{|l|c|}
\hline \multicolumn{1}{|c|}{ Группы по основному занятию } & $\begin{array}{c}\text { Доля имеющих } \\
\text { кредиты, \% }\end{array}$ \\
\hline Работаю по найму на постоянной долговременной основе & 68,7 \\
\hline Официально зарегистрированный бизнесмен, ИП, самозанятый & 64,4 \\
\hline Работаю в своем ЛПХ & 44,9 \\
\hline $\begin{array}{l}\text { Неофициально работаю по устным договоренностям, работаю } \\
\text { временно, работаю сам на себя }\end{array}$ & 44,1 \\
\hline Учусь в дневном техникуме, училище, колледже, вузе & 13,8 \\
\hline Нахожусь на пенсии по возрасту, инвалидности & 40,0 \\
\hline Веду домашнее хозяйство & 30,1 \\
\hline $\begin{array}{l}\text { Временно не работаю, безработный, зарегистрирован в службе } \\
\text { занятости }\end{array}$ & 41,3 \\
\hline $\begin{array}{l}\text { Временно не работаю, безработный, не зарегистрирован в службе } \\
\text { занятости }\end{array}$ & 41,5 \\
\hline
\end{tabular}

Источник: итоги социологического исследования, проведенного в Республике Тыва в 2021 г. Центром исследования социальной структуры и социального расслоения Института социологиИ ФНИСЦ РАН.

По уровню материального благосостояния и в соответствии с самооценкой респондентов самую активную группу, обращающуюся в банки за кредитами, составили те, кто оценили свой материальный статус как «денег хватает на питание и одежду, но на крупные покупки приходится откладывать или брать кредит» $-58,40 \%$. Тревожным является показатель наличия кредитов у 43,10\% респондентов, которые, по их собственной оценке, испытывают недостаток финансовых средств даже на питание. Обращение к заемным средствам в виде кредитов является общепринятой финансовой практикой во всех опрошенных социально-демографических группах вне зависимости от материального положения с дифференциацией лишь в степени распространенности кредитов в той или иной группе. При этом женщины $(56,0 \%)$ чаще имеют кредиты, чем мужчины $(47,1 \%)$.

Как показано в табл. 2, в структуре целей получения банковских кредитов наибольший вес имеют покупка жилья по ипотеке $-21,8 \%$ и оплата долгов и займов $-20,1 \%$.

В совокупности для 24\% опрошенных характерно получение кредитов на покупку продуктов питания, одежды, обуви, на оплату ЖКХ, аренду жилья, приобретение угля. Использование заемных средств на удовлетворение базовых и текущих потребностей является одним из значимых маркеров бедности населения, с одной стороны, и недостаточным уровнем финансовой грамотности населения - с другой. На приобретение еды, одежды, обуви берут кредиты преимущественно молодые люди в возрасте 18-34 лет.

Очень мал удельный вес респондентов, получающих кредиты на цели, имеющие экономический эффект, - на поддержку бизнеса, КФХ, ЛПХ $(5,6 \%)$.

Тревожным показателем является тот факт, что $20,1 \%$ опрошенных оформляют банковские кредиты на погашение иных долгов и займов, что показывает 
Таблииа 2

Цели получения кредита

\begin{tabular}{|l|c|}
\hline \multicolumn{1}{|c|}{ Цели получения кредита } & $\begin{array}{c}\text { Доля в совокупности } \\
\text { имеющих кредит, \% }\end{array}$ \\
\hline На покупку еды, одежды, обуви & 12,0 \\
\hline На оплату ЖКХ, аренду жилья, покупку угля & 12,0 \\
\hline На покупку жилья по ипотеке & 21,8 \\
\hline $\begin{array}{l}\text { На приобретение самых необходимых лекарств и } \\
\text { медикаментов, оплату экстренной медпомощи }\end{array}$ & 5,0 \\
\hline На оплату долгов, займов & 20,1 \\
\hline Для поддержки бизнеса, КФХ, ЛПХ & 5,6 \\
\hline Другое (что именно) & 15,7 \\
\hline
\end{tabular}

Источник: итоги социологического исследования, проведенного в Республике Тыва в 2021 г. Центром исследования социальной структуры и социального расслоения Института социологии ФНИСЦ РАН.

наличие вторых и последующих кругов долгов, которые направляются на погашение предыдущих. Таким образом, наращиваются объемы кредитной задолженности. Ситуацию усугубляют долги перед физическими лицами.

Финансовое поведение населения республики характеризуется тем, что для ежемесячной оплаты задолженности по кредиту респонденты берут в долг финансовые средства у физических лиц. В ходе исследования 2019 г. 65,1\% домохозяйств отметили, что берут в долг деньги у родственников и знакомых. При этом 30,8\% из них берут деньги на оплату кредитов и займов, 29,8\% - на самые необходимые расходы, $16,7 \%$ - на приобретение самых необходимых лекарств и медикаментов, оплату экстренной медпомощи. $37,5 \%$ берут в долг 1 раз в два-три месяца, 29,4\% - каждый месяц, 20,6\% - несколько раз в год и реже, $12,5 \%$ - 1 раз в четыре-шесть месяцев.

По итогам глубинных интервью 2021 г. можно выделить несколько важных фактов среди причин распространенности кредитов среди населения.

1. Практически все участники интервью едины в том, что без кредитов нет возможности осуществлять крупные покупки (автомобиль, мебель, бытовая техника) и строить жилье. Имеющихся доходов, несмотря на наличие работы и стабильную зарплату, недостаточно для крупных расходов и формирования сбережений. С этой точки зрения кредиты - необходимая и вынужденная мера, вызванная доходной бедностью. «Я и моя супруга получаем пенсию, я также продолжаю работать. Кредиты беру с 2009 г. Действующий кредит будет уже последним в моей жизни. Считаю, что кредиты - это хорошая возможность что-то полезное сделать: машину покупали на средства кредита, дом строим. Без кредитов на наши доходы не смогли бы ничего купить, и тем более строить дом» (ПМА, 2021, 3 - мужчина, 62 года, работающий пенсионер, имеет среднее профессиональное образование).

2. Использование кредитов стало долговременной и многоразовой практикой, при которой за погашением одного кредита следует оформление нового. Таким образом, для респондентов использование банковских кредитов является частью пролонгированной во времени жизненной стратегии. Предстоящие крупные расходы, вызванные разными жизненными событиями, респонденты также связывают с будущими кредитами. Для участников 
интервью накопление необходимой суммы для крупных покупок не представляется возможным и является малопривлекательной стратегией. В этой связи одним из плюсов кредитов респонденты называют именно возможность сделать приобретения «здесь и сейчас», несмотря на отсутствие финансовых средств на текущий момент. «Я почти 20 лет беспрерывно пользуюсь кредитами. Погашаю кредит, беру новый или до завершения действующего кредита беру еще один. Эти кредиты использовались для покупки автомобиля, мебели, бытовой техники, гаража, земельного участка, для строительства дома. Все крупные покупки были сделаны за счет кредитов, так как доходов не хватает, большая часть из них уходит на выплаты по действующим кредитам. Поэтому формировать сбережения также не получается. В ближайшем будущем также планирую оформить новый кредит, так как предстоят крупные расходы, связанные с бракосочетанием сына. Плюсы кредитов в том, что нужные покупки можно сразу сделать. Минусы в том, что большую часть дохода приходится направлять на их погашение» (ПМА, 2021, 4 - женщина 49 лет, работает, имеет высшее образование).

3. Как показали интервью, ежемесячные платежи составляют от $40 \%$ до $100 \%$ доходов семьи, что является высоким риском в случае потери работы и источника доходов, а также указывает на отрицательное сальдо семейного бюджета с учетом текущих ежедневных расходов и существенные депривации, вызванные отсутствием средств в бюджете семьи. «У нас с супругой 6 действующих кредитов, которые мы брали, чтобы построить дом и на другие нужды. Оформляем кредит, строим, этих средств недостаточно для завершения строительства, обращаемся за новым кредитом. Машину купили на кредитные средства, чтобы возить детей. Есть и мелкие кредиты, которые мы оформляли для покупки техники, телефонов, например. Наш с супругой суммарный доход составляет 40 тыс. рублей, и он полностью направляется на погашение кредитов, на жизнь нам помогают родители» (ПМА, 2021, 1 - мужчина, 33 года, женат, работает, имеет высшее образование, двое детей).

4. Помимо вынужденной необходимости обращения за кредитами в банки из-за недостатка средств в бюджете семьи, поддержание общепринятого, социально одобряемого уровня жизни является одним из мотивов приобретения в кредит статусных предметов, стоимость которых превышает имеющийся уровень доходов. Все более распространяющиеся ценности потребительского общества, стремление к желаемому уровню потребления также ведут к закредитованности той части населения, которая по формальному уровню доходов не относится к бедным. «Мы все хотим жить не хуже других или быть, как все, иметь машину, хороший дом и современную технику. А поддерживать достойный уровень жизни можно, лишь прибегая к кредитам» (ПМА 2021, 5 - женщина, 50 лет, работает, имеет высшее образование).

Таким образом, доходная бедность толкает людей на оформление кредитов, и в то же время кредиты во многом являются причиной фактической бедности, и зачастую из-за недостатка финансовой грамотности. Кредиты при невысоких доходах и наличии детей, которые находятся на иждивении у родителей, при отсутствии накоплений означают высокие финансовые и социальные риски для семей.

В исследованиях в рамках поведенческой экономики подчеркивается, что хроническая депривация негативно влияет на принятие правильных решений в повседневной жизни [Durvasula 2014: 6]. Одним из эффектов, наблюдаемых в ситуациях дефицита, является туннелирование (примером может служить ситуация, когда решается насущная необходимость оплатить просроченный счет за счет дорогостоящего кредита, который усугубляет дефицит [Filho, 
Paiva 2017: 3]). Как указывается в материалах Всемирного банка, неправильные финансовые решения не обусловлены отклоняющимися ценностями или культурой бедности: бедные люди, как и не бедные, подвержены влиянию определенных когнитивных, психологических и социальных ограничений в принятии решений. Именно контекст бедности влияет на принятие решений, в т.ч. финансовых. В такой ситуации выход из бедности становится практически невозможным ${ }^{1}$.

Переход от расходной стратегии к стратегии накопления и приумножения требует повышения финансовой грамотности семей, и это должно стать отдельным направлением государственной социальной политики по снижению бедности. Дефицит финансовой грамотности населения наблюдается в целом по стране, и эта тема достаточно активно обсуждается в отечественных исследованиях [Козырева, Смирнов 2016: 134; Ярашева 2017: 73; Аликперова 2020: 43].

Сбережения. С кредитным поведением населения неразрывно связаны возможности к сбережению, от которого зависит в т.ч. финансовая устойчивость бюджетов домохозяйств. Вопрос наличия некой «подушки безопасности» приобрел особую актуальность в период пандемии коронавирусной инфекции, которая болезненно отразилась в первую очередь на малом, среднем бизнесе, на неформальном секторе рынка труда.

По результатам исследования уровня финансовой грамотности, проведенного Аналитическим центром НАФИ в рамках проекта Минфина России «Содействие повышению уровня финансовой грамотности населения и развитию финансового образования в Российской Федерации» в 2020 г. во всех 85 субъектах РФ, было выявлено, что в случае потери основного источника дохода $42 \%$ россиян смогут оплачивать все необходимые расходы (без займов у близких и оформления кредитов) не более одного месяца. В среднем при потере работы накоплений россиян хватит на 63 дня².

Что касается населения Республики Тыва, то, как показано выше, дефицит средств на текущие расходы, высокая кредитная нагрузка, отвлекающая из бюджета домохозяйств существенную часть поступающих доходов, не позволяет большинству домохозяйств формировать сбережения. По итогам исследования 2019 г. только 7,7\% домохозяйств ежемесячно откладывали средства в виде сбережений, 21,8\% - от случая к случаю, 70,4\% не имели сбережений по причине дефицита средств на текущие расходы.

Социологическое исследование брачных пар, проведенное автором в декабре 2020 - январе 2021 г., показало практически аналогичные результаты: 68,7\% респондентов не имеют сбережений, только $28,1 \%$ указали, что откладывают средства. Обращает на себя внимание тот факт, что городские жители чаще, чем сельские, имеют сбережения - 17,3\% и $10,8 \%$ соответственно.

Анализ данных Росстата за 2016-2020 гг. показывает, что есть позитивная динамика - наблюдается рост суммарного объема и объема на душу населения вкладов (депозитов) физических лиц в рублях и иностранной валюте, привлеченных кредитными организациями в Туве ${ }^{3}$. Однако рост объемов вкладов может формироваться за счет только высокодоходных групп населения.

\footnotetext{
1 Mind, Society, and Behavior. World Development Report 2015. N.Y.: World Bank Group. P. 80.

2 Портрет финансово грамотного человека. - Аналитический иентр НАФИ. 09.07.2020. Доступ: https://nafi.ru/analytics/portret-finansovo-gramotnogo-cheloveka/ (проверено 01.02.2022).

3 Финансы России 2020: статистический сборник. - Сайт Федеральной службы государственной статистики. Доступ: https://rosstat.gov.ru/folder/210/document/13237 (проверено 01.02.2022).
} 
Если сравнить общий объем вкладов (депозитов) физических лиц с объемом задолженности по кредитам, предоставленным кредитными организациями физическим лицам, т.е. посмотреть их соотношение, то последний превышает объем вкладов более чем в 3 раза (см. табл. 3).

Таблица 3

Соотношение объемов вкладов (депозитов) и задолженности по кредитам в Республике Тыва, млн руб.

\begin{tabular}{|c|c|c|}
\hline Годы & $\begin{array}{c}\text { Объем вкладов (депозитов) } \\
\text { физических лиц, привлеченных } \\
\text { кредитными организациями }\end{array}$ & $\begin{array}{c}\text { Объем задолженности по кредитам в } \\
\text { рублях, предоставленных кредитными } \\
\text { организациями физическим лицам }\end{array}$ \\
\hline 2016 & 6546 & 19395 \\
\hline 2017 & 7731 & 20454 \\
\hline 2018 & 8850 & 23418 \\
\hline 2019 & 9711 & 30136 \\
\hline 2020 & 10765 & 36849 \\
\hline
\end{tabular}

Источник: Финансы России 2020: статистический сборник. - Сайт Федеральной службы государственной статистики. Доступ: https://rosstat.gov.ru/folder/210/document/13237 (проверено 01.02.2022).

Как показано в табл. 4, прогрессивный рост наблюдается как по вкладам, так и по задолженности населения Республики Тыва практически с одинаковым темпом: по сравнению с 2016 г. объем вкладов в 2019 г. вырос в 1,6 раза, в то время как за этот же период объем задолженности вырос в 1,8 раза. Соответственно выросла доля обязательных платежей в структуре использования общего объема денежных доходов населения с 11,7\% в 2010 г. до 16,4\% в 2019 г. ${ }^{1}$

Относительно сберегательного поведения населения в научной литературе существуют разные теоретические подходы и множество эмпирических исследований. В работе Н. Лоэйза, К. Шмидт-Гебелла и Л. Сервена в панели детерминантов сберегательного поведения наряду с такими показателями, как доходы, темпы роста, инфляция, денежные запасы, потребление населения, пенсионная система, распределение богатств и доходов, урбанизованность населения, есть демографический показатель [Loayza, Smidt-Hebbel, Servèn 2000: 398]. Эта детерминанта, на наш взгляд, важна для понимания сберегательного поведения населения республики в контексте нашего исследования. Как отмечают указанные авторы, в современном мире рост коэффициента иждивенцев - лиц молодого и пожилого возрастов имеет тенденцию негативно влиять на сбережения физических лиц. Со ссылкой на экономический обзор Всемирного банка они показали, что рост в 3,5\% иждивенцев молодого возраста в структуре населения ведет к снижению объема сбережений на $1 \%$, а увеличение числа лиц пожилого возраста негативно влияет на сбережения в 2 раза больше [Loayza, Smidt-Hebbel, Servèn 2000: 401].

Если следовать этой логике, чем больше в структуре населения молодых и пожилых, тем меньше население откладывает средств на будущее в виде сбережений. В Республике Тыва мы видим устойчивую тенденцию уменьшения числа трудоспособного населения в демографической структуре населения. В 2005 г. трудоспособное население составляло 61,3\% населения, в 2019 г. -

1 Регионы России. Социально-экономические показатели 2020 (пред. ред. колл. С.М. Окладников). М.: Федеральная служба государственной статистики. 2020. С. 284. 
$54,8 \% 1$. Снижение доли населения трудоспособного возраста происходит в т.ч. за счет высокой рождаемости. Полагаем, что имеющийся коэффициент демографической нагрузки при невысоком уровне среднедушевых денежных доходов и невысоком уровне занятости детерминируют отсутствие сбережений у большинства домохозяйств и существенный разрыв в соотношении объемов вкладов (депозитов) и задолженности по кредитам у населения республики в целом. Финансовые возможности откладывать средства в виде сбережений снижаются пропорционально росту числа детей в семье.

Пример государственной политики других стран показывает, что сберегательное поведение населения тоже подлежит управлению и формированию. Как показали Дж. Акерлоф и Р. Шиллер на примере своих студентов, людям сложно осознавать смысл и цели сбережений, долгосрочные возможности, которые открывает сложный процент, и недостаточность сбережений - это весьма распространенное явление в большинстве развитых стран [Акерлоф, Шиллер 2010: 149, 155]. Вместе с тем они указывают, что, в отличие от распространенной в США и, в меньшей степени, в Западной Европе культуры потребления, направленной на расходование, есть страны Юго-Восточной Азии, такие как Сингапур и Китай, которые смогли достичь очень высокого уровня сбережений населения благодаря соответствующей государственной политике. В Китае еще в 1990-е гг. валовой объем личных сбережений достигал $20 \%$ в консолидированном объеме сбережений, и его уровень остается высоким до сих пор [Акерлоф, Шиллер 2010: 57, 161].

Выводы. Республика Тыва имеет самый высокий суммарный показатель по уровню проникновения кредитования. Объективными факторами распространения кредитов является высокий удельный вес населения с денежными доходами ниже величины прожиточного минимума.

Финансовое поведение опрошенных в большинстве случаев свидетельствует о превышении расходов над доходами не только из-за низкого уровня реальных располагаемых доходов в условиях многодетности семей, но и из-за недостатка финансовой грамотности.

Доступность услуг МФО для населения с низкими доходами является одним из социальных рисков и ведет к повышению депривационной бедности получателей этих услуг.

Кроме названных причин, анализ данных социологических исследований показал, что пользование кредитами является практикой, характерной для всех опрошенных социально-демографических групп населения вне зависимости от материального положения и доходной стратификации.

Закредитованность населения и наращивание объемов задолженности происходит в т.ч. из-за того, что для оплаты существующих долгов и займов респонденты прибегают к новым кредитным обязательствам, а также к займам у физических лиц.

В таких условиях для многих семей сложно перейти к сберегательной стратегии. Помимо экономических мер стимулирования регионального рынка труда, нужны меры по повышению финансовой грамотности, формированию сберегательных стратегий у населения.

\section{Список литературы}

Акерлоф Дж., Шиллер Р. 2010. Spiritus Animalis, или как человеческая психология управляет экономикой, и почему это важно для мирового капитализма (пер. с англ.). М.: Юнайтед Пресс. 273 с.

\footnotetext{
1 Там же. С. 54.
} 
Аликперова Н.В. 2020. Финансовое просвещение россиян: классификация целевых групп. - Уровень жизии населения регионов России. Т. 16. № 2. С. 42-50.

Голенкова 3.Т., Голиусова Ю.В., Сушко П.Е. 2020. Региональные особенности доходной стратификации в контексте занятости и финансового поведения (на примере Республики Тыва). - Россия реформирующаяся: ежегодник. Вып. 18 (отв. ред. М.К. Горшков). М.: Новый хронограф. С. 33-54.

Голиусова Ю.В., Кефели В.Б. 2019. Финансовое поведение населения Республики Тыва. - Особенности социальной стратификации в Республике Тыва. Информационно-аналитический бюллетень ФНИСЦ РАН. № 3. С. 59-70.

Козырева П.М., Смирнов А.И. 2016. Особенности и тенденции адаптации россиян к изменяющимся условиям в постсоветский период. - Россия реформирующаяся: ежегодник (отв. ред. М.К. Горшков). М.: Новый хронограф. Вып. 14. С. 133-171.

Медведева Е.И., Ярашева А.В., Тореев В.Б., Крошилин С.В. 2016. Финансовые стратегии жителей российских городов. - Национальные интересы: приоритеты и безопасность. № 3. С. 4-14.

Овчарова Л.Н., Красильникова М.Д., Пишняк А.И. 2020. Мониторинг социально-экономического положения и социального самочувствия населения: итоги 2019 г. Апрель 2020 (под ред. Л.Н. Овчаровой). М.: НИУ ВШЭ. 44 с.

Особенности социальной стратификации в Республике Тыва. Информационноаналитический бюллетень ФНИСЦ РАН (ИНАБ). 2019. № 3.71 с.

Шубаева В.Г., Наумов В.Н. 2015. Модель экономического поведения потребителей финансовых услуг в современных условиях. - Известия СанктПетербурского государственного экономического университета. № 5(95). C. $78-84$.

Ярашева А.В. 2017. Экономические ожидания населения и сберегательные стратегии россиян. - Экономика и управление. № 11(145). С. 67-74.

Durvasula R. 2014. What Can Behavioral Economics Tell Us about Depletion and Decision Making? - Poverty and Inequality. Special Blog Series: the War on Poverty. 50 year later. P. 6-7. URL: https://www.apa.org/pi/ses/resources/publications/ poverty-and-inequality.pdf (accessed 01.02.2022).

Filho A.C., Paiva L. H. 2017. Behavioral Insights in Poverty Reduction Policy. Policy Research Brief. International Policy Center for Inclusive Growth. P. 1-5. URL: https://www.researchgate.net/publication/319276741_Behavioural_insights_in_ poverty_reduction_policies (accessed 01.02.2022).

Loayza N., Smidt-Hebbel K., Servèn L. 2000. Saving in Countries: an Overview. The World Bank Review. January 2000. P. 393-414.

Poluektova O.V., Efremova M.V., Breugelmans S.M. 2015. Poverty and Psychology: working papers. Series: Psychology WP BRP 49/PSY/2015. 20 p. URL: https://www. hse.ru/data/2015/12/04/1080734458/49PSY2015\%20(2).pdf (accessed 01.02.2022). 
NATSAK Organa Dorjuevna, Cand.Sci. (Philos.), Academic Secretary, Tuvan Institute for Humanities and Applied Social and Economic Research under the Government of the Republic of Tuva (4 Kochetova St, Kyzyl, Republic of Tuva, Russia,667000;nod695596@gmail.com)

\title{
FINANCIAL AND ECONOMIC STRATEGIES OF TUVAN FAMILIES (on the materials of sociological research)
}

\begin{abstract}
The article analyzes the financial and economic strategies of modern Tuvan families based on the materials of sociological studies conducted in the Republic of Tuva in 2019 and 2021. The features of the credit and savings behavior of the surveyed population in the context of different socio-demographic groups were studied using, among other things, statistical data on income, debt burden of the population.

The reason for the high level of credit penetration into the practice of modern Tuvan families is not only an insufficient level of financial literacy and a culture of savings, but also objective monetary poverty. The article shows that the high level of demographic burden in the republic does not contribute to the development of savings and savings strategies. Based on the results of the analysis, the author concludes that the actual poverty of the population will grow unless a special policy is realized to develop the regional economy, as well as to increase financial literacy and a culture of savings among the population of the republic.
\end{abstract}

Keywords: household income and expenses, loans, savings, economy of Tuvan families, financial literacy, secondary employment 